\section{A randomised controlled trial comparing laparoscopy with laparo- tomy in the management of women with ruptured ectopic pregnancy}

To the Editor: We read with interest the article that appeared in the March 2017 issue of $S A M J^{[1]}$ and would like to commend the authors on the publication of this important topic, demonstrating the advantages of laparoscopic surgery for the management of women with ruptured ectopic pregnancy (REP).

Even though the authors randomised the patients, in our opinion they failed to categorise the group of patients they refer to by not quantifying the haemoperitoneum. The description of such patients can be difficult, as there is no agreed standardisation. Do they refer to REP as including women in whom haemoperitoneum was demonstrated on an ultrasound scan and, if that was the case, what was the amount of blood in the peritoneal cavity? Does REP include the $30 \%$ of women who present with unquantified haemoperitoneum, ${ }^{[2]}$ or the $6 \%$ of patients with significant haemoperitoneum $(\geq 800 \mathrm{~mL})$, as defined by Odejinmi et al. ${ }^{[3]}$

Although the authors demonstrate the advantages of the operative laparoscopy approach to the management of ectopic pregnancy, particularly in the low-cost setting, in eliminating patients with an $\mathrm{Hb}<8 \mathrm{~g} / \mathrm{dL}$, a pulse rate $<100$ beats/minute, and a systolic blood pressure $<90 \mathrm{mmHg}$, they may have been managing patients with minimal haemoperitoneum, whose outcomes would have been no different from women with unruptured ectopic pregnancies. This can also be inferred by the small difference in pre- and postoperative $\mathrm{Hb}$ levels in both groups of randomised patients.

Furthermore, Snyman et al. ${ }^{[1]}$ have highlighted that laparoscopy took significantly longer than laparotomy. Surely, the pivotal fact in a REP should be the time taken to haemostasis - not the total operating time. Moreover, the increased time is most probably a function of the experience of the operating surgeon, as there is ample evidence from units with experienced laparoscopic surgeons that laparoscopy is equally quick - if not quicker - compared with laparotomy. We fear that these data, if presented without qualification, might send a message reverting modern accepted practices.

In our institution, we have been able to offer operative laparoscopy to nearly all women, irrespective of location of the ectopic pregnancy or haemodynamic status, but this has taken time, effort and education of all involved in the management of ectopic pregnancy. ${ }^{[4]}$

It is hoped that, using their randomised study as a baseline, the authors will be able to update the academic community on their progress and changing trends in the laparoscopic management of ectopic pregnancy in a low-cost setting in a few years' time.

\section{F Odejinmi, R Oliver}

Department of Gynaecology, Whipps Cross University Hospital, Barts Health NHS Trust, London, UK

reeba.oliver@gmail.com

1. Snyman LC, Makulana T, Makin JD. A randomised trial comparing laparoscopy with laparotomy in the management of women with ruptured ectopic pregnancy. S Afr Med J 2017;107(3):258-263. https:// doi.org/10.7196/SAMJ.2017.v107i3.11447

2. Falcone T, Mascha EJ, Goldberg JM, Falconi LL, Mohla G, Attaran M. A study of risk factors for ruptured tubal ectopic pregnancy. J Women's Health 1998;7(4):459-463.

3. Odejin $\mathrm{S}$. Odefin I, Sangrithi M, Olown O. Operative laparoscopy as the mainstay treatment of haenody numicaly (10. org/10.1016/j.jmig. 2010.11 .00

Odejinmi F, Rizzuto I, Oliver R, Alalade A, Agarwal N, Olowu O. Beyond guidelines: Effectiveness of a programme in achieving operative laparoscopy for all women requiring surgical management of ectopic pregnancy. Gynecol Obstet Invest 2015;80:46-53. https://doi.org/10.1159/000371763

Prof. L C Snyman et al. respond: Thank you for the opportunity to respond to the letter by F Odejinmi and R Oliver. We would like to thank them for their interest in our work and the important issues raised.
The objective of our study was to include patients who, by definition, did not present with a diagnosis of unruptured ectopic pregnancy, as the trials referred to in the Cochrane Review were limited to patients with unruptured ectopic pregnancies. ${ }^{[1]}$ We agree that the term 'ruptured ectopic pregnancy' does not accurately describe the cohort of women in our study, as many of these patients were bleeding into the peritoneal cavity without having demonstrable tubal rupture. The clinical diagnosis of a ruptured or bleeding ectopic pregnancy with any amount of haemoperitoneum was sufficient for inclusion in the study. Patients with unruptured ectopic pregnancies were excluded.

The haemodynamic exclusion criteria were arbitrarily chosen after discussion with the anaesthetic department, as we were reluctant to include patients who were haemodynamically unstable, mainly owing to safety and ethical considerations. In our setting, laparoscopic management of these patients was not the standard of care at the time the study was conducted. We agree that these parameters did select for cases with less severe amounts of bleeding. The postoperative $\mathrm{Hb}$ values referred to did not reflect the severity of the cases, but demonstrated the quality of intraoperative resuscitation - evident from the statistically significant difference in blood transfusion requirements between the two groups. The laparotomy group required more blood transfusions (mainly commenced intraoperatively), and the postoperative $\mathrm{Hb}$ levels suggest that these transfusions were appropriate. We are, therefore, of the opinion that the group of patients described in our article are different from patients with unruptured ectopic pregnancies without haemoperitoneum. There is also enough other evidence supporting the view that patients with severe haemoperitoneum and even hypovolaemic shock can be safely managed by laparoscopic surgery. ${ }^{[2,3]}$ We have shown (Table 4), ${ }^{[4]}$ with multinomial logistic regression, that the increased operating time is a function of the procedure - not only the function of the operator. We do agree that with more experience the operating time can be shorter, but we do not think that the total theatre time will be the same or shorter as for the open procedure, as is the case in most laparoscopic operations. The reason for commenting on operating and theatre time is that in the context of a limited-resource setting, such as ours, theatre time is a scarce commodity, with several disciplines requiring and competing for after hours' emergency theatre time. These theatre lists are managed and prioritised by the anaesthetic staff on call. In our experience, the time issue remains the main stumbling block in ensuring that all eligible women receive emergency laparoscopic surgery where indicated, as the dictum eloquently phrased by Dargent ${ }^{[5]}$ that 'we can do it faster open' is still a reality in the minds of theatre nursing and anaesthetic staff.

\section{C Snyman, T Makulana, J D Makin}

Department of Obstetrics and Gynaecology, Faculty of Health Sciences, School of Medicine, University of Pretoria and Kalafong Provincial Tertiary Hospital, Pretoria, South Africa

leon.snyman@up.ac.za

1. Hajenius PJ, Mol F, Mol BW, Bossuyt PM, Ankum WM, van der Veen F Interventions for tubal ectopic pregnancy Cochrane Database Syst Rev 2007(1):CD000324. https://doi.org/10.1002/14651858.CD000324. pub2

2. Cohen A, Almog B, Satel A, Lessing JB, Tsafrir Z, Levin I. Laparoscopy versus laparotomy in the management of ectopic pregnancy with massive hemoperitoneum. Int J Gynaecol Obstet 2013;123(2):139-141. https://doi.org/10.1016/j.ijgo.2013.05.014

3. Rizzuto MI, Oliver R, Odejinmi F. Laparoscopic management of ectopic pregnancy in the presence of a significant haemoperitoneum. Arch Gynecol Obstet 2008;277(5):433-436. https://doi.org/10.1007/ s00404-007-0473-7

4. Snyman LC, Makulana T, Makin JD. A randomised trial comparing laparoscopy with laparotomy in the management of women with ruptured ectopic pregnancy. S Afr Med J 2017;107(3):258-263. https:// doi.org/10.7196/SAMJ.2017.v107i3.11447

5. Dargent DFG. Laparoscopic surgery in gynecologic oncology - some disputable applications and one fruitful indication. Gynecol Oncol 2005;97(3):725-726. https://doi.org/10.1016/j.ygyno.2005.03.046

S Afr Med J 2017;107(5):359. DOI:10.7196/SAMJ.2017.v107i5.12446 